\title{
Feeding response of the tropical copepod Acartia erythraea to short-term thermal stress: More animal-derived food was consumed
}

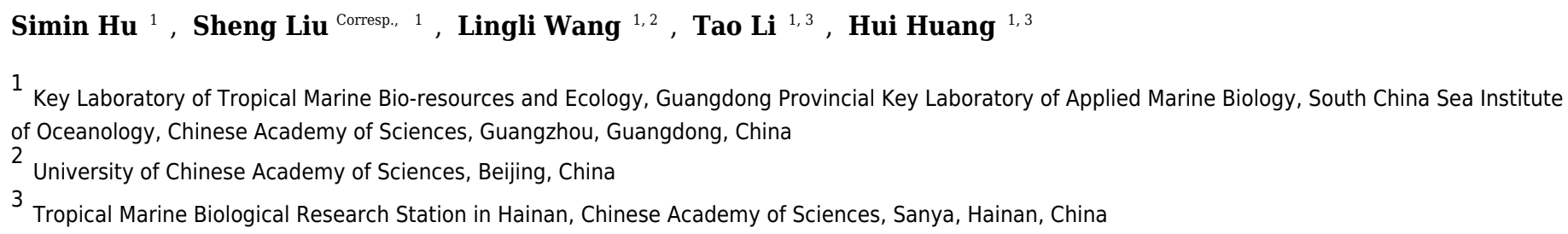

The objective of this study was to explore the feeding response of tropical copepods to short-term thermal shock and provide insight into the potential impact of coastal power plants on the trophic dynamics of tropical coastal ecosystems. Feeding experiments were conducted at three different temperatures $\left(29^{\circ} \mathrm{C}, 33^{\circ} \mathrm{C}\right.$, and $\left.35^{\circ} \mathrm{C}\right)$ using the copepod Acartia erythraea, collected from Sanya Bay, China. The grazing rate of $A$. erythraea decreased dramatically in the high temperature treatment. Analysis of 18S rDNA clone libraries revealed that the diet of copepods from different treatments was mainly comprised of diatoms, metazoans, and protozoans; $A$. erythraea exhibited an obvious feeding preference shift with temperature, with a change from a diatom-dominated diet at $29{ }^{\circ} \mathrm{C}$ to a metazoan-dominated diet at $35^{\circ} \mathrm{C}$, and the omnivory index shifted from 0.1 to 2.84 correspondingly. Furthermore, $A$. erythraea showed a positive feeding response to plant food (i.e., phytoplankton and land plants) in the control treatment $\left(29^{\circ} \mathrm{C}\right)$, but a positive response to animal prey (i.e., metazoans and protozoans) at temperatures exceeding $33^{\circ} \mathrm{C}$, as evaluated by the Ivlev's selectivity index. Our results suggest that copepods could regulate their food intake by considering their energy demands when exposed to short-term thermal stress, which might influence the pathway of materials moving up the trophic system. However, further studies are required to elucidate the effects of elevated temperature on feeding of different organisms in order to predict the influence of thermal pollution on the food web of tropical coastal ecosystems. 


\section{Feeding response of the tropical copepod Acartia erythraea to}

\section{2 short-term thermal stress: More animal-derived food was}

\section{3 consumed}

4 Simin $\mathrm{Hu}^{1}$, Sheng Liu ${ }^{1 *}$, Lingli Wang ${ }^{1,2}$, Tao Li ${ }^{1,3}$, Hui Huang ${ }^{1,3}$

$5 \quad{ }^{1}$ Key Laboratory of Tropical Marine Bio-resources and Ecology, Guangdong Provincial Key Laboratory

6 of Applied Marine Biology, South China Sea Institute of Oceanology, Chinese Academy of Sciences,

7 Guangzhou 510301, China

$8 \quad{ }^{2}$ University of Chinese Academy of Sciences, Beijing, 100049, China

$9{ }^{3}$ Tropical Marine Biological Research Station in Hainan, Chinese Academy of Sciences, Sanya, 572000,

10 China

11

12

13

14

15

16

17

18

19

20

21

22

Corresponding author:

31 Sheng Liu

32164 West Xingang Road, Guangzhou, Guangdong, 510301, PR China.

33 E-mail address: $\underline{\text { shliu@ } @ \text { scsio.ac.cn }}$ 
34

35

36

37

38

39

40

41

42

43

44

45

46

47

48

49

50

51

52

53

54

\section{ABSTRACT}

The objective of this study was to explore the feeding response of tropical copepods to shortterm thermal shock and provide insight into the potential impact of coastal power plants on the trophic dynamics of tropical coastal ecosystems. Feeding experiments were conducted at three different temperatures $\left(29^{\circ} \mathrm{C}, 33^{\circ} \mathrm{C}\right.$, and $\left.35^{\circ} \mathrm{C}\right)$ using the copepod Acartia erythraea, collected from Sanya Bay, China. The grazing rate of A. erythraea decreased dramatically in the high temperature treatment. Analysis of $18 \mathrm{~S}$ rDNA clone libraries revealed that the diet of copepods from different treatments was mainly comprised of diatoms, metazoans, and protozoans; $A$. erythraea exhibited an obvious feeding preference shift with temperature, with a change from a diatom-dominated diet at $29^{\circ} \mathrm{C}$ to a metazoan-dominated diet at $35^{\circ} \mathrm{C}$, and the omnivory index shifted from 0.1 to 2.84 correspondingly. Furthermore, A. erythraea showed a positive feeding response to plant food (i.e., phytoplankton and land plants) in the control treatment $\left(29^{\circ} \mathrm{C}\right)$, but a positive response to animal prey (i.e., metazoans and protozoans) at temperatures exceeding 33 ${ }^{\circ} \mathrm{C}$, as evaluated by the Ivlev's selectivity index. Our results suggest that copepods could regulate their food intake by considering their energy demands when exposed to short-term thermal stress, which might influence the pathway of materials moving up the trophic system. However, further studies are required to elucidate the effects of elevated temperature on feeding of different organisms in order to predict the influence of thermal pollution on the food web of tropical coastal ecosystems. 


\section{INTRODUCTION}

Demand for electrical energy generation is increasing in coastal areas due to growing urbanization. Seawater-cooled power plants provide an economical way to generate electricity and growing numbers of power plants are operating in coastal areas, especially in subtropical and tropical regions (Poornima et al., 2006). The thermal effluent water discharged from the cooling systems of coastal power plants can cause various environmental changes, with temperature elevation being the main impact on coastal habitats (Jiang et al., 2009); organisms are subjected to acute thermal shock with a temperature increase of approximately $6-10{ }^{\circ} \mathrm{C}$ above ambient temperature in tropical zones (Poornima et al., 2006; Jiang et al., 2009). Temperature increases can alter physiological processes and metabolic rates at the species level, and biomass and distribution at the community scale (Sommer et al., 2012; Lewandowska et al., 2014a). Furthermore, asynchronous responses by individual species to variations in temperature can further disrupt their interactions with other species and lead to mismatches in marine food webs (Lewandowska et al., 2014b). Thus, information on variations in trophic interactions under thermal stress is vital for understanding the functioning of coastal ecosystems, especially in tropical ecosystems where organisms generally live at ambient temperatures that are relatively close to their upper thermal limits (Hoegh-Guldberg, 1999; Worthington et al., 2015).

Planktonic organisms are usually small, with short generation times and weak motility. These characteristics make them especially vulnerable to sea temperature increases (Hays, Richardson \& Robinson, 2005). Among the marine plankton, copepods represent the major group of secondary producers and play a key role in the cycling of nutrients and energy in marine ecosystems by forming a trophodynamic link from primary production to higher trophic levels (Colombo-Hixson et al., 2013). Understanding the feeding responses of copepods to thermal stress could provide insight into their survival and also the dynamics of coastal food webs. Copepods commonly inhabit the upper ocean layers $(0-100 \mathrm{~m})$, where they are exposed directly to temperature increases due to thermal effluents. These increases in temperature are fast and dramatic; therefore, short-term responses to thermal stimulation are important for species 
82

83

84

survival and adaption, especially for thermally sensitive species (Werbrouck et al., 2016).

Feeding is an important basic process for organisms and is influenced by temperature both directly and indirectly (Sommer et al., 2012). Water temperature increases could affect the feeding process of copepods indirectly by exerting effects on food availability. Cell size, photosynthetic rates, and nutritional status (e.g., lipid composition, degree of fatty acid saturation, etc.) of phytoplankton are all affected by increased temperature (Rousch, Bingham \& Sommer, 2003; Zhang et al., 2012). These changes in the nutritional status of food items might influence their palatability (Peter \& Sommer, 2012; Lewandowska et al., 2014b). High temperatures can also affect physiological traits (e.g., body size, life cycle length, respiration, metabolic processes) of copepods directly (Shiah et al., 2006; Jiang et al., 2008; Worthington et al., 2015; Dziuba, Cerbin \&Wejnerowski, 2017). Temperature increases of $3{ }^{\circ} \mathrm{C}$ have been shown to promote the growth and metabolic rate of copepods near power plants, especially in winter (Wojtal-Frankiewicz, 2012). However, slightly higher mortality of copepods was observed in the outlet regions of power plants than in the inlet regions, and copepod species with larger body sizes were more susceptible to thermal stress than smaller ones (Jiang et al., 2008; 2009). Changes in copepod community structure could occur due to species-specific thermal tolerances and favor the dominance of copepods with smaller body sizes in areas near power plants. Elevated temperatures could also reduce the swimming ability of copepods and affect their feeding behavior (Larsen, Madsen \& Riisgård, 2008). Copepods can adjust their feeding strategy according to food availability; it has been reported that copepods are able to efficiently adjust their digestive enzyme pattern to a new food source within days (Kreibich et al., 2011). Copepods switched from feeding on phytoplankton to grazing on ciliates under warming conditions and exhibited stronger top-down control over protozooplankton under increased temperatures because protozooplankton had faster growth rates (Lewandowska et al., 2014a; Aberle et al., 2015).

Most studies in this field have been mesocosm experiments designed to predict the effects of global warming on the productivity of copepod communities in mid- and high-latitude 
109

110

111

112

113

114

115

116

117

118

119

120

121

122

123

124

125

126

127

128

129

130

131

132

133

134

areas/temperate seas (Kjellerup et al., 2012). Copepods in tropical nearshore waters are relatively close to their upper thermal limit, so any further increase in the ambient water temperature may severely affect their feeding behavior (Chew \& Chong, 2016). However, little is known about the feeding responses of copepods exposed to thermal stress in tropical areas.

Acartia is a genus of small copepods that dominate zooplankton communities in temperate and subtropical coastal ecosystems. Acartia spp. usually lack storage capabilities and are vulnerable to environmental changes that require rapid responses to changing food availability (Shin et al., 2003). Acartia erythraea was selected for this study because it is an important coastal copepod in the South China Sea (Liu et al., 2010). Acartia erythraea is one of the dominant copepod species in subtropical (e.g., Daya Bay) and tropical (e.g., Sanya Bay) waters in summer and fall (Hu et al., 2012). Previous studies have shown that elevated temperatures clearly affect the feeding behavior of Acartia (Henriksen et al., 2012); however, their response to extreme thermal stress remains unclear. In the present study, a short-term feeding study on $A$. erythraea was conducted using the natural plankton community as a food resource under different temperature treatments, in order to investigate the rapid feeding response of copepods to thermal stress.

\section{MATERIALS AND METHODS}

\section{Copepod collection and gut clearance}

Zooplankton were collected at dusk on April 23, 2014, using surface plankton net-tows (diameter $50 \mathrm{~cm}$, mesh size $505 \mu \mathrm{m}$ ) in the coastal waters of Luhuitou, Sanya Bay $\left(109^{\circ} 28^{\prime} \mathrm{E}\right.$, $\left.18^{\circ} 12^{\prime} \mathrm{N}\right)$. Live copepods were kept in a 1-L plastic container and transferred to the laboratory for gut evacuation. For the feeding experiment, surface seawater was also collected using a clean 25$\mathrm{L}$ bucket in the same region.

Copepods were immediately transferred into several $500-\mathrm{mL}$ beakers containing $0.45 \mu \mathrm{m}$ filtered seawater for gut evacuation that was performed in the dark for $>48 \mathrm{~h}$. Every $4 \mathrm{~h}$ during the clearance period, the copepods were gently collected using $200-\mu \mathrm{m}$ mesh and rinsed $3-5$ 
135

136

137

138

139

140

141

142

143

144

145

146

147

148

149

150

151

152

153

154

155

156

157

158

159

160

161

times with fresh seawater (FSW) to remove any attached detritus, and then transferred to FSW to fully empty their gut contents. After this procedure, healthy adult A. erythraea females of similar size were selected for the feeding experiment.

\section{Feeding experiment}

According to the ambient field temperature, the feeding experiment was performed at three different temperatures: $29{ }^{\circ} \mathrm{C}, 33{ }^{\circ} \mathrm{C}$, and $35^{\circ} \mathrm{C}$. The temperature of the sampling site was $29^{\circ} \mathrm{C}$, therefore this temperature treatment was used as the control. According to previous studies, a 6 ${ }^{\circ} \mathrm{C}$ temperature increase was observed in the waters of thermal discharge-affected areas in tropical zones (Jiang et al., 2009); therefore, $33{ }^{\circ} \mathrm{C}$ and $35^{\circ} \mathrm{C}$ were used as the experimental temperatures, with the goal of investigating the rapid feeding response of copepods to acute heat shock.

Twenty liters of collected seawater were gently filtered through $0.45-\mu \mathrm{m}$ polycarbonate membranes and then re-suspended in $5 \mathrm{~L}$ of FSW to concentrate. After thorough mixing, a 50 $\mathrm{mL}$ sample of concentrated seawater was removed and immediately fixed with Lugol's solution for cell counting as the prey concentration before the experiment. Another $200 \mathrm{~mL}$ seawater was taken and centrifuged at $3000 \times g$ for $15 \mathrm{~min}$, and the concentrated samples were pelleted by centrifugation at $12000 \times g$ for 5 min. The cell pellets were re-suspended in $0.5 \mathrm{~mL}$ DNA buffer for DNA extraction. The concentrated seawater was then aliquoted into twelve $200-\mathrm{mL}$ polycarbonate bottles to serve as a source of prey. For each treatment, a control group, without the addition of copepods, was prepared to monitor the growth of phytoplankton during the short exposure period. Each treatment had three replicates. Fifty adult individuals of $A$. erythraea were added to each experimental bottle and then incubated, at different temperatures, for $4 \mathrm{~h}$ in tanks with flowing seawater culture systems. After a $4 \mathrm{~h}$ incubation period, individual copepods were gently collected using $200 \mu \mathrm{m}$ mesh and immediately fixed with neutral Lugol's solution to avoid defecation. Neutral Lugol's (no acetic acid added) was found to be effective in preserving DNA of phytoplankton and other copepod associated organisms (Zhang and Lin, 2002; Hu et al., 2014). There was no mortality of copepods during the short-term experiments. At the end of the 
162

163

164

165

166

167

168

169

170

171

172

173

174

175

176

177

178

179

180

181

182

183

184

experiments, $50 \mathrm{~mL}$ water samples were collected from each treatment and preserved with Lugol's solution as the prey concentration after the experiment. There was no measurable growth of phytoplankton during this period.

\section{Microscopic analysis of phytoplankton in seawater}

Seawater samples were allowed to settle for $2 \mathrm{~d}$ in the dark, and then concentrated to $1 \mathrm{~mL}$; they were then identified and enumerated in a Sedgwick-Rafter counting chamber under an Olympus BX51 microscope. The cell density of the seawater before and after the feeding experiment was obtained for the calculation of feeding parameters.

\section{Grazing rate and filter rate based on the phytoplankton cells}

The grazing rate (GR, cells ind ${ }^{-1} \mathrm{~h}^{-1}$ ) was calculated using the following equation:

$$
\mathrm{GR}=V \times \frac{C_{0}-C_{t}}{N \times t}
$$

The filter rate (FR, $\mathrm{mL}$ ind ${ }^{-1} \mathrm{~h}^{-1}$ ) was calculated using the following equation:

$$
\mathrm{FR}=V \times \frac{\ln C_{0}-\ln C_{t}}{N \times t}
$$

where $\mathrm{V}(\mathrm{ml})$ is the volume of seawater in the experimental bottle, $N$ is the number of copepods in the bottle, and $\mathrm{t}(\mathrm{h})$ is the incubation time. $C_{0}$ and $C_{t}\left(\right.$ cells $\left.\mathrm{mL}^{-1}\right)$ are the prey concentrations (phytoplankton cells in the experimental seawater) before and after the feeding experiment, respectively.

\section{Molecular analysis of copepod diet}

A previously reported procedure was followed (see Hu et al., 2014). Briefly, the sorted fixed copepod samples were thoroughly rinsed $>3$ times, with autoclaved $0.45-\mu \mathrm{m}$-filtered seawater and again with sterilized water several times. Copepods were examined under stereomicroscopy to ensure no attachment of other visible organisms on the body surface and then homogenized in a microfuge tube using a disposable micro pestle (Eppendorf, Hamburg, 
Germany). DNA from all copepod and seawater samples was extracted following the CTAB protocol. The DNA samples were PCR amplified using a PCR protocol based on a CEEC primer set (Hu et al., 2014). The PCR amplifications were concentrated using a Zymo DNA Clean \& Concentrator TM-25 Kit. The target bands $(\sim 0.8 \mathrm{~kb})$ were recovered from a $1 \%$ agarose gel using Zymoclean $^{\mathrm{TM}}$ Gel DNA Recovery Kit (Zymo Research, Irvine, CA, USA). The purified PCR products were ligated into a PMD18-T vector (Takara Bio Inc., Kusatsu, Japan) and transformed to $\mathrm{DH}-5 \alpha$ competent cells (Takara Bio Inc.). Approximately 50-80 clones for each copepod sample and 150-200 clones for each seawater sample were randomly picked and sequenced (Invitrogen sequencing company).

\section{Phylogenetic analysis of sequence data}

Sequences obtained were trimmed of primer sequences and then searched against the GenBank database using the Basic Local Alignment Search Tool. The identified sequences were represented by the highest homologous sequences. Identified clones were categorized into plantorigin and animal-origin, and then a heat-map analysis was conducted using R (R Core Team, 2017). Our sequences were then aligned with the best hits using CLUSTAL W (1.8). The resulting alignment was imported into MEGA 6.0 to identify the best-fit nucleotide substitution model. The best-fit model Kimura 2, with gamma distribution $(\mathrm{K} 2+\mathrm{G})$, was then employed for maximum likelihood (ML) analysis. The reliability of the tree topology was evaluated using bootstrap analysis with 1000 replicates for ML analysis (Hu et al., 2014). Diversity indices (Chao-1, Simpson, and Shannon) were estimated using Past 3.05 to evaluate the sequencing depth of all the samples.

\section{Omnivory index and Ivlev's selectivity index}

A percentage of each sequences from the whole clone library of each copepod sample was used to estimate the relative diet proportion. The trophic level and percentage were recorded to calculate the omnivory index (OI). This index was first introduced in the initial version of the Eco-path software and is calculated as the variance of the trophic level of a consumer's prey 
211 groups:

$$
O I_{i}=\sum_{j=1}^{n}\left(T L_{j}-\left(T L_{i}-1\right)\right)^{2} \bullet D C_{i j}
$$

213

214

215

216

217

218

219

220

221

222

223

224

225

226

227

228

229

230

231

232

233

234

235

where $T L_{j}$ is the trophic level of prey $j, T L_{i}$ is the trophic level of the predator $i$, and, $D C_{i j}$ is the proportion prey $j$ constitutes to the diet of predator $i$. When the omnivory index value is zero, the consumer in question is specialized, i.e., it feeds on a single trophic level. A large value indicates that the consumer feeds on many trophic levels, or in other words is more omnivorous (Pauly, Soriano-Bartz \& Palomares, 1993).

Ivlev's selectivity index (Ivlev, 1961) was also used to determine the selectivity pattern of A. erythraea in the incubation experiment:

$$
E_{i}=\left(r_{i}-P_{i}\right) /\left(r_{i}+P_{i}\right)
$$

where $E_{i}$ is the Ivlev's selectivity index, $r_{i}$ is the relative abundance of prey $i$ in the diet of $A$. erythraea and $P i$ is the relative abundance of the prey in ambient seawater. Observed values ranged from -1 to 1 , where -1 indicates prey avoidance, 0 indicates that a prey species is being ingested at the same proportion as it is found in the environment, and 1 indicates a preference for a determined prey.

\section{RESULTS}

\section{Grazing rate and filter rate of $A$. erythraea in different temperature treatments}

Generally, the grazing rate and filter rate of A. erythraea showed an overall decrease with increasing temperature (Table 1). Compared with the control group $\left(29^{\circ} \mathrm{C}\right)$, the feeding of $A$. erythraea was increased slightly at $33{ }^{\circ} \mathrm{C}$, with the grazing rate increasing from $40.04 \pm 0.07$ to $40.14 \pm 0.11$ cells ind ${ }^{-1} \mathrm{~h}^{-1}$ and the filter rate increasing from $2.59 \pm 0.04$ to $3.34 \pm 0.11 \mathrm{~mL} \mathrm{ind}^{-1}$ $\mathrm{h}^{-1}$, respectively. At $35^{\circ} \mathrm{C}$, the grazing rate of $A$. erythraea dramatically decreased to $28.20 \pm$ 0.14 cells ind ${ }^{-1} \mathrm{~h}^{-1}$, and the filter rate decreased to $0.44 \pm 0.11 \mathrm{~mL}$ ind $^{-1} \mathrm{~h}^{-1}$. Increased temperature influenced the feeding behavior of $A$. erythraea; their ability to filter feed, especially phytoplankton, was limited when the temperature was higher than $33{ }^{\circ} \mathrm{C}$. 


\section{Dietary composition of $\boldsymbol{A}$. erythraea from different temperature treatments}

18S rDNA clone libraries were constructed for $A$. erythraea fed at different temperatures, as well as the plankton community of the concentrated field seawater used in the experiment. Based on randomly sequenced clones, a total of 12, 10, and 10 taxa of prey were detected for $A$. erythraea at $29^{\circ} \mathrm{C}, 33^{\circ} \mathrm{C}$, and $35^{\circ} \mathrm{C}$, respectively (Table 2). Although Chao-1 estimates indicated that the actual numbers of taxa were likely to be 19,10 , and 11 , respectively, the prey taxa detected in the experimental groups $\left(33^{\circ} \mathrm{C}\right.$ and $\left.35^{\circ} \mathrm{C}\right)$ were similar to the Chao-1 estimates, indicating an adequate coverage of diversity to demonstrate the effects of elevated temperature.

Despite the incomplete recovery of the entire dietary diversity in the control group $\left(29^{\circ} \mathrm{C}\right)$, prey taxa found in the samples consisted of a wide phylogenetic range of organisms, including diatoms, metazoans, protozoans, and fungi, as well as land plants (Fig. 1). In the $29{ }^{\circ} \mathrm{C}$ treatment, land plants (99\% identical to Hordeum jubatum AF168852.1) and diatoms (98\% identical to Cylindrotheca closterium LC054954.1) dominated the diet, accounting for $46 \%$ and $36 \%$, respectively. Other numerically minor constituents such as fungi, protozoans, and Synurophyceae were also detected. In the $33^{\circ} \mathrm{C}$ treatment, the same diatom species (Cylindrotheca closterium) was the most abundant prey taxa, comprising almost $58 \%$ of the diet. Other prey items belonged to the metazoans, protozoans, dinoflagellates, Synurophyceae, and fungi. The dietary spectrum of $A$. erythraea at $29^{\circ} \mathrm{C}$ and $33^{\circ} \mathrm{C}$ was similar. However, in the 35 ${ }^{\circ} \mathrm{C}$ treatment, a less diverse array of prey taxa was detected, with the contribution of metazoan taxa increasing up to $70 \%$, but diatoms decreased to $16 \%$ (Fig. 1).

\section{Feeding preference changes with increasing temperature}

Although the dietary spectrum was similar at different temperatures, the species numbers and relative proportions of each prey group (e.g., diatoms, metazoans, and protozoans) differed (Fig. 1). The omnivory index of $A$. erythraea at $29^{\circ} \mathrm{C}$ and $33^{\circ} \mathrm{C}$ was 0.1 and 0.24 , respectively, while a remarkable increase (as high as 2.84) was observed in the $35^{\circ} \mathrm{C}$ treatment. This indicates a more carnivorous feeding habit under temperature stress. The feeding habit of $A$. erythraea showed a likely shift from herbivory to carnivory when the temperature exceeded $33{ }^{\circ} \mathrm{C}$. 
263 Furthermore, we divided all the prey items of $A$. erythraea from the different temperature

264 treatments into three groups, metazoa, protozoa, and vege-prey (includes phytoplankton and

265 plants), and calculated their Ivlev's selectivity index. Acartia erythraea showed positive feeding

266 on vege-prey at $29{ }^{\circ} \mathrm{C}$ and $33{ }^{\circ} \mathrm{C}$, but negative feeding on vege-prey at $35^{\circ} \mathrm{C}$. For metazoan prey,

267 A. erythraea showed negative feeding at $29^{\circ} \mathrm{C}$ but strong positive feeding in the $35^{\circ} \mathrm{C}$

268 treatment, and the Ivlev's index increased from -0.62 to 0.75 (Fig. 2).

\section{DISCUSSION}

270 Many studies have evaluated the environmental impact of elevated seawater temperatures

271 near coastal power plants on marine organisms and coastal ecosystems (Jiang et al., 2009; Li et

272 al., 2011; Sommer \& Lewandowska, 2011; Lewandowska et al., 2014a). Most of these studies

273 have focused on community structure or physiological responses in mesocosm incubations;

274 however, little attention has been paid to trophic interactions, especially feeding responses to

275 short-term thermal stress (O'Connor et al., 2009; Saiz \& Calbet, 2011). Knowledge of the dietary

276 composition of secondary consumers, such as copepods, exposed to warming environments is an

277 important step in understanding exchanges of material and energy transfer through food webs

278 affected by thermal effluents. Our results strongly suggest that increased temperature affected the

279 active feeding behavior of $A$. erythraea when the temperature was higher than $33^{\circ} \mathrm{C}$; prey items

280 showed reduced diversity and there was an obvious shift to carnivory during short-term exposure

281 to high temperatures $\left(35^{\circ} \mathrm{C}\right)$.

282 As small omnivores, Acartia spp. usually dominate coastal zooplankton communities in

283 food-sufficient seasons as they cannot adapt to low food concentrations. However, they can

284 apply an opportunistic feeding strategy depending on prey concentration (McKinnon, Duggan \&

285 De'ath, 2005). Accordingly, the diet of A. erythraea in the present study was more diverse than

286 that of other copepods in Sanya Bay, as identified by molecular detection; large amount of land-

287 plant detritus were found in their diets (Hu et al., 2015). In the present study, a total of 25 taxa

288 (genera or species) were represented in the diet, especially phytoplankton food. Diatoms were

289 the most important prey group of $A$. erythraea and they dominated the dietary composition in the 
290

291

292

293

294

295

296

297

298

299

300

301

302

303

304

305

306

307

308

309

310

311

312

313

314

315

316

$29{ }^{\circ} \mathrm{C}$ and $33{ }^{\circ} \mathrm{C}$ treatments, with a small fraction of diatoms being consumed at $35^{\circ} \mathrm{C}$. These results confirmed that diatoms are an excellent food for copepods; as previously reported, they can produce large quantities of polyunsaturated fatty acids (PUFA), especially eicosapentaenoic acid (EPA). Some diatom species (e.g., Thalassiosira weissflogii) can support the entire growth phase of some Acartia spp. (e.g., A. tonsa) (Dunstan et al., 1994). Cylindrotheca closterium was the most abundant diatom species in the diet of $A$. erythraea in all the three treatments as it was the dominant phytoplankton species in the seawater and could be easily predated upon by copepods. The coastal coral waters of Sanya Bay are reportedly food-limited in terms of phytoplankton and $\mathrm{Hu}$ et al. (2015) found that copepods consumed large amounts of land plant detritus as a supplementary food source. This finding is consistent with our results from the control group, with land plants identified as the dominant food group. In comparison, diatoms were also abundant prey in the $29{ }^{\circ} \mathrm{C}$ and $33{ }^{\circ} \mathrm{C}$ treatments. The concentrated seawater we used for our incubation feeding experiments might have affected food availability, which was considered to be one of the major factors influencing copepod feeding rates in the field (Saiz \& Calbet, 2011). In the present study, the concentration process increased the density of phytoplankton and might have decreased the energetic costs of copepod foraging on phytoplankton prey (Alcaraz et al., 2014). In the $35^{\circ} \mathrm{C}$ treatment, only a small fraction of algal prey was identified; therefore, it is possible that elevated temperatures reduced copepod predation on phytoplankton.

Previous studies have shown that the optimum temperature for feeding of Acartia spp. was $25-30{ }^{\circ} \mathrm{C}$, and grazing/filtering rates decreased beyond this range (Milione \& Zeng, 2008). In the present study, we calculated the exact grazing/filtering rate of copepods based on phytoplankton cells, and found that the grazing rate of $A$. erythraea slightly increased in the $33{ }^{\circ} \mathrm{C}$ treatment, but decreased dramatically at $35^{\circ} \mathrm{C}$, indicating that the ability of copepods to actively feed might be weakened due to their reduced swimming ability at elevated temperatures (Larsen, Madsen \& Riisgård, 2008). This is further supported by the observation that A. erythraea consumed prey with stronger swimming abilities, such as dinoflagellates and other protozoans, at $33{ }^{\circ} \mathrm{C}$, whereas 
317 at $35^{\circ} \mathrm{C}$, it consumed more benthic diatom species (e.g., Licmophora, Navicula, Cylindrotheca).

318 However, the most abundant prey group at elevated temperatures was metazoans (e.g.,

319 crustaceans, Chaetognatha). These prey might have originated from detritus-containing

320 chaetognath or crustacean remnants, as chaetognaths and macrura larvae were abundant

321 zooplankton groups in the sampling area, and have been reported to be prey for other copepods

322 in Sanya Bay (Yin et al., 2004; Hu et al., 2015).

323 Except for diet diversity changes among the different treatments, the most obvious

324

325

326

327

328

329

330

331

332

333

334

335

336

337

338

339

340

341

342

343

difference between the different temperatures was the shift from plant-originated food items (i.e., phytoplankton and land plants) to animal prey (i.e., protozoans and metazoans). In the control treatment, plant-originated food items dominated the diet $(>80 \%)$, while animal-derived foods only accounted for $4 \%$. At $33{ }^{\circ} \mathrm{C}$, although plant-originated food still comprised the majority of food items $(\sim 75 \%)$, the proportion of protozoans increased to $10 \%$. This finding is consistent with previous results that showed that zooplankton preferred to feed on micro-zooplankton during periods of increased temperature (Lewandowska et al., 2014a). On the other hand, the proportion of phytoplankton (mainly diatoms) in the diet decreased dramatically to $16 \%$ at 35 ${ }^{\circ} \mathrm{C}$, while metazoan food items increased to almost $62 \%$. Furthermore, the OI increased from 0.1 at $29^{\circ} \mathrm{C}$ to 2.84 at $35^{\circ} \mathrm{C}$, indicating that $A$. erythraea turned to carnivory as a result of higher temperatures. These animal-based foods might be important at elevated temperatures as they have superior protein content quality compared to phytoplankton, and might be more easily assimilated by copepods as they have similar nutritional profiles (Wang et al., 2014). These results suggested that elevated temperature might narrow the food spectrum of copepods, but they are able to compensate by consuming more high energy prey items to sustain their metabolic needs (Hammock et al., 2016).

Previous studies have shown that zooplankton metabolic demands increased faster than their feeding rates in response to increased temperature, resulting in weaker interactions between zooplankton and phytoplankton and copepod top-down control over phytoplankton populations (Rall et al., 2010). In other words, energy available from phytoplankton as food items may be 
344 insufficient to support their metabolic needs; therefore, copepods might turn to consuming prey

345 that can provide higher levels of energy. As reported by Clarke, Holmes \& Gore (1992), the

346 energy content of lipids, proteins, and carbohydrates was $39.5 \mathrm{~kJ} \mathrm{~g}^{-1}, 23.9 \mathrm{~kJ} \mathrm{~g}^{-1}$, and $17.5 \mathrm{~kJ} \mathrm{~g}^{-1}$,

347 respectively. Considering energy availability, metazoan prey (e.g., tunicates, chaetognaths, and

348 crustacean amphipods) could provide copepods with more energy than phytoplankton (Wang et

349 al., 2014). Additionally, the energy supplied by a metazoan diet with high levels of lipids and

350 proteins, may be more accessible and easily utilized by copepods than plant food items,

351 guaranteeing baseline metabolic demands during periods of stressful temperature conditions

352 (Colombo-Hixson et al., 2013). This was an important feeding strategy for copepods in tropical

353 seas near coastal power plants where abnormally high seawater temperatures, elevated up to 6-

$35410^{\circ} \mathrm{C}$, were reported (Poornima et al., 2006).

Similar food availability in the incubation experiment masked, to some extent, the effects of

356

357

358

359

360

361

362

363

364

365

366

367

368

369

370 temperature on feeding in the $33{ }^{\circ} \mathrm{C}$ treatment, as the diversity of the diet was slightly higher

than that in the control group and the dominant prey group was the same as the control. Field data also showed that temperature might have a weaker effect on copepod feeding rates in natural waters because they would physiologically adapt to the feeding conditions (food availability) (Saiz \& Calbet, 2011). Therefore, the feeding habit shift observed in the incubation experiment, which eliminated the influence of food availability and adaptation due to the short duration time, might reflect the exact effects of temperature on copepod feeding. The short-term response of tropical copepods found here was a little different from copepods in temperate seas, which prefer high-carbon-content phytoplankton food items at higher temperatures in natural seas (Boersma et al., 2016). For tropical copepods, especially Acartia, optimizing energy acquisition for survival might be more important, similar to enhanced consumption of heterotrophic organisms in typical tropical habits (corals) under thermal stress (Borell \& Bischof, 2008). Comprehensive studies should be conducted to clarify whether this short-term feeding response is a beneficial response for population-level thermal adaption, or just guarantees immediate survival. 


\section{CONCLUSIONS}

Elevated temperatures affect the feeding behavior of $A$. erythraea by reducing their active feeding on phytoplankton and causing them to rely more on animal prey. Taken together, the findings of this study indicate that copepods seemed to adjust their feeding behavior to prioritize energy acquisition under short-term thermal stress. Although phytoplankton might be consumed by micro-zooplankton, previous studies have suggested an increased trophic pathway through protozooplankton under conditions of warming oceans as microzooplankton responded more quickly to the temperature changes. This change could reduce the efficiency of the upward trophic transfer of matter and energy flow though mesozooplankton under short term stress conditions, and thereby affect the efficiency of ecosystem cycling near coastal power plants. Due to the increasing need to generate electricity in coastal areas, coastal (fossil fuel or nuclear reactors) power plants must rely on seawater for cooling until renewable sources of electric production can be widely applied. Additionally, elevated seawater temperature caused by ongoing global warming will aggravate the impacts of thermal discharge on organisms near power plant outlets. Thus, our results indicate that rising seawater temperatures caused by coastal power plants can be of great significance in changing trophic pathways in regional seas. However, considering the variability in the responses of different species to thermal stress, further studies are needed on the feeding responses of tropical mesozooplankton at different trophic levels to precisely evaluate the effects of rising temperature on material and energy transfer through the food web.

\section{ACKNOWLEDGMENTS}

We are grateful to Cuilian Xu of University of Chinese Academy of Sciences for her help with sample collection and experimental setup.

\section{REFERENCES}

Aberle N, Malzahn AM, Lewandowska AM, Sommer U. 2015. Some like it hot: the protozooplankton-copepod link in a warming ocean. Marine Ecology Progrocess Series 519:103-113 DOI 10.3354/meps11081. 
398

399

400

401

402

403

404

405

406

407

408

409

410

411

412

413

414

415

416

417

418

419

420

421

422

423

424

425

426

427

428

429

430

431

432

433

434

435

436

437

438

Alcaraz M, Felipe J, Grote U, Arashkevich E, Nikishina A. 2014. Life in a warming ocean: thermal thresholds and metabolic balance of arctic zooplankton. Journal of Plankton Research 36(1):3-10 DOI 10.1093/plankt/fbt111

Boersma M, Mathew KA, Niehoff B, Schoo KL, Franco-Santos RM, Meunier CL. 2016. Temperature-driven changes in the diet preference of omnivorous copepods: no more meat when it's hot? Ecology Letters 19:1386-1388 DOI 10.1111/ele.12541

Borell EM, Bischof K. 2008. Feeding sustains photosynthetic quantum yield of a scleractinian coral during thermal stress. Oecologia 157(4):593-601 DOI 10.1007/s00442-008-1102-2

Chew LL, Chong VC. 2016. Response of marine copepods to a changing tropical environment: winners, losers and implications. PeerJ 4:e2052 DOI 10.7717/peerj.2052

Clarke A, Holmes LJ, Gore DJ. 1992. Proximate and elemental composition of gelatinous zooplankton from the Southern Ocean. Journal of Experimental Marine Biology and Ecology 155(1):55-68 DOI 10.1016/0022-0981(92)90027-8

Colombo-Hixson SM, Olsen RE, Tibbetts SM, Lall SP. 2013. Evaluation of Calanus finmarchicus copepod meal in practical diets for juvenile Atlantic halibut (Hippoglossus hippoglossus). Aquacult Nutrition 19(5):687-700 DOI 10.1111/anu.12016

Dunstan GA, Volkman JK, Barrett SM, Leroi JM, Jeffrey SW. 1994. Essential polyunsaturated fatty acids from 14 species of diatom (Bacillariophyceae). Phytochemistry 35(1):155-161. DOI 10.1016/S0031-9422(00)90525-9

Dziuba MK, Cerbin S, Wejnerowski L. 2017. Is bigger better? A possibility for adaptation of Daphnia to filamentous cyanobacteria in the face of global warming. Hydrobiologia 798(1):105-118. DOI 10.1007/s10750-015-2438-3

Hammock BG, Lesmeister S, Flores I, Bradburd GS, Hammock FH, The SJ. 2016. Low food availability narrows the tolerance of the copepod Eurytemora affinis to salinity, but not to temperature. Estuaries and Coasts 39(1):1-12 DOI 10.1007/s12237-015-9988-5

Hays GC, Richardson AJ, Robinson C. 2005. Climate change and marine plankton. TRENDS in Ecology and Evolution 20(6):337-344.

Henriksen MV, Jung-Madsen S, Nielsen TG, Møller EF, Henriksen KV, Markager S, Hansen BW. 2012. Effects of temperature and food availability on feeding and egg production of Calanus hyperboreus from Disko Bay, western Greenland. Marine Ecology Progress Series 447(1):109-126 DOI 10.3354/meps09421

Hoegh-Guldberg O. 1999. Climate change, coral bleaching and the future of the world's coral reefs. Marine and Freshwater Research 50(8):839-866 DOI 10.1071/MF99078

Jiang Z, Zeng J, Chen Q, Huang Y, Xu XQ, Liao YB, Shou L, Liu JJ. 2008. Tolerance of copepods to short-term thermal stress caused by coastal power stations. Journal of Thermal Biology 33(7):419-423 DOI 10.1016/j.jtherbio.2008.06.008

Jiang Z, Zeng JN, Chen QZ, Huang YJ, Liao YB, Xu XQ, Zheng P. 2009. Potential impact of rising seawater temperature on copepods due to coastal power plants in subtropical areas. Journal of Experimental Marine Biology and Ecology 368(2):196-201 DOI 10.1016/j.jembe.2008.10.016

Hu S, Guo Z, Li T, Carpenter EJ, Liu S, Lin S. 2014. Detecting in situ copepod diet diversity 
439

440

using molecular technique: Development of a Copepod/ Symbiotic Ciliate-Excluding Eukaryote-Inclusive PCR protocol. PloS One 9:e103528 DOI 10.1371/journal.pone.0103528

Hu S, Guo Z, Li T, Xu C, Huang H, Liu S, Lin S. 2015. Molecular analysis of in situ diets of coral reef copepods: evidence of terrestrial plant detritus food source in Sanya Bay, China. Journal of Plankon Research 37(2):363-371 DOI 10.1093/plankt/fbv014

Hu S, Liu S, Li T, Guo Z. 2012. Advances in feeding ecology of Acartia. Acta Ecologica Sinica (In Chinese with English abstract) 32:5870-5877.

Kreibich T, Saborowski R, Hagen W, Niehoff B. 2011. Influence of short-term nutritional variations on digestive enzyme and fatty acid patterns of the calanoid copepod Temora longicornis. Journal of Experimental Marine Biology and Ecology 407(2):182-189. DOI 10.1016/j.jembe.2011.06.013

Larsen PS, Madsen CV, Riisgård HU. 2008. Effect of temperature and viscosity on swimming velocity of the copepod Acartia tonsa, brine shrimp Artemia salina and rotifer Brachionus plicatilis. Aquatic Biology 1:47-54. DOI 10.3354/ab00093

Lewandowska AM, Boyce DG, Hofmann M, Matthiessen B, Sommer U, Worm B. 2014a. Effects of sea surface warming on marine plankton. Ecology Letters 17(5):614-623 DOI $10.1111 /$ ele. 12265

Lewandowska AM, Hillebrand H, Lengfellner K, Sommer U. 2014b. Temperature effects on phytoplankton diversity-The zooplankton link. Journal of Sea Research 85:359-364 DOI 10.1016/j.seares.2013.07.003

Li T, Liu S, Huang L, Huang H, Lian J, Yan Y, Lin S. 2011. Diatom to dinoflagellate shift in the summer phytoplankton community in a bay impacted by nuclear power plant thermal effluent. Marine Ecology Progress Series 424:75-85 DOI 10.3354/meps08974

Liu S, Li T, Huang H, Guo Z, Huang L, Wang W. 2010. Feeding efficiency of a marine copepod Acartia erythraea on eight different algal diets. Acta Ecologica Sinica 30(1):2226 DOI 10.1016/j.chnaes.2009.12.004

McKinnon AD, Duggan S, De'ath G. 2005. Mesozooplankton dynamics in nearshore waters of the Great Barrier Reef. Estuarine, Coastal and Shelf Science 63(4):e497-511 DOI 10.1016/j.ecss.2004.12.011

Milione M, Zeng C. 2008. The effects of temperature and salinity on population growth and egg hatching success of the tropical calanoid copepod, Acartia sinjiensis. Aquaculture 275(14): 116-123 DOI 10.1016/j.aquaculture.2007.12.010

O'Connor MI, Piehler MF, Leech DM, Anton A, Bruno JF. 2009. Warming and resource availability shift food web structure and metabolism. PLoS Biology 7(9):e1000178 DOI 10.1371/annotation/73c277f8-421a-4843-9171-403be1a014c7

Pauly D, Soriano-Bartz ML, Palomares MLD. 1993. Improved construction, parameterization and interpretation of steady-state ecosystem models. In: Christensen V and Pauly D, ed.Trophic Models of Aquatic Ecosystems, ICLARM Conference proceedings, 1-13

Peter KH, Sommer U. 2012. Phytoplankton cell size: Intra- and interspecific effects of warming and grazing. PloS One 7:e49632 DOI 10.1371/journal.pone.0049632 
480

481

482

483

484

485

486

487

488

489

490

491

492

493

494

495

496

497

498

499

500

501

502

503

504

505

506

507

508

509

510

511

512

513

514

515

516

517

518

519

520

Poornima EH, Rajaduraia M, Rao VNR, Narasimhan SV, Venugopalan VP, 2006. Use of coastal waters as condenser coolant in electric power plants: Impaction on phytoplankton and primary productivity. Journal of Thermal Biology 31(7):556-564 DOI 10.1016/j.jtherbio.2006.05.009

Rall BC, Vucic-Pestic O, Ehnes RB, Emmerson M, Brose U. 2010. Temperature, predatorprey interaction strength and population stability. Global Change Biology 16(8):21452157. DOI: $10.1111 /$ j.1365-2486.2009.02124.x

Rousch JM, Bingham SE, Sommer MR. 2003. Changes in fatty acid profiles of thermointolerant and thermo-tolerant marine diatoms during temperature stress. Journal of Experimental Marine Biology and Ecology 295(2):145-146 DOI 10.1016/S00220981(03)00293-4

Saiz E, Calbet A. 2011. Copepod feeding in the ocean: scaling patterns, composition of their diet and the bias of estimates due to microzooplankton grazing during incubations. Hydrobiologia 666(1):181-196 DOI 10.1007/s10750-010-0421-6

Shiah FK, Wu T, Li K, Kao S, Tseng YF, Chung J, Jan S. 2006. Thermal effects on heterotrophic processes in a coastal ecosystem adjacent to a nuclear power plant. Marine Ecology Progress Series 309:55-65.

Shin K, Jang MC, Jang PK, Ju SJ, Lee TK, Chang M. 2003. Influence of food quality on egg production and viability of the marine planktonic copepod Acartia omorii. Progress in Oceanography 57(3-4):265-277 DOI 10.1016/S0079-6611(03)00101-0

Sommer U, Adrian R, Barbara B, Winder M. 2012. The response of temperature aquatic ecosystems to global warming: novel insights from a multidisciplinary project. Marine Biology 159(11):2367-2377 DOI 10.1007/s00227-012-2085-4

Sommer U, Lewandowska AM. 2011. Climate change and the phytoplankton spring bloom: warming and overwintering zooplankton have similar effects on phytoplankton. Global Change Biology 17(1):154-162 DOI 10.1111/j.1365-2486.2010.02182.x

Wang M, O'Rorke R, Nodder S, Jeffs AG. 2014. Nutritional composition of potential zooplankton prey of the spiny lobster phyllosoma (Jasus edwardsii). Marine and Freshwater Research 64(4):337-349 DOI 10.1071/MF13048

Werbrouck E, Gansbeke DV, Vanreusel A, Mensens C, Troch MD. 2016. Temperatureinduced changes in fatty acid dynamic of the intertidal grazer Platychelipus littoralis (Crustacea, Copepoda, Harpacticoida): Insights from a short-term feeding experiment. Journal of Thermal Biology 57:44-53 DOI 10.1016/j.jtherbio.2016.02.002

Wojtal-Frankiewicz A. 2012. The effects of global warming on Daphnia spp. population dynamics: a review. Aquatic Ecology 46(1):37-53 DOI 10.1007/s10452-011-9380-x

Worthington TA, Shaw PJ, Daffern JR, Langford TEL. 2015. The effects of a thermal discharge on the macroinvertebrate community of a large British river: implications for climate change. Hydrobiologia 753:81-95 DOI 10.1007/s10750-015-2197-1

Yin J, Zhang G, Tan Y, Huang L, Li K. 2004. Species composition and quantitative distribution of zooplankton in Sanya Bay, Hainan Province, China. Journal of Tropical Oceanography (In Chinese with English abstract), 23:1-9. 
521 Zhang M, Yu Y, Yang Z, Kong F. 2012. Photochemical responses of phytoplankton to rapid increasing-temperature process. Phycological Research 60(3):199-207 DOI

524 


\section{Figure legends}

526 Fig. 1. Phylogenetic affiliations and taxonomic distribution of prey organisms of the copepod

527 Acartia erythraea at different temperatures. The phylogenetic tree was established for prey taxa 528 with the ML method and 1000 bootstrap replicates, which is presented on the left. The dietary 529 composition of $A$. erythraea at different temperatures is shown on the right, and different colors 530 represent the relative percentage of each prey group.

531 Fig. 2. Ivlev's index of Acartia erythraea at different temperatures. Vege-prey represents dietary 532 organisms from phytoplankton and land plants. 


\section{Table 1 (on next page)}

Grazing rate and filter rate of Acartia erythraea in different incubation treatments 
1 Table 1 Grazing rate and filter rate of Acartia erythraea in different incubation treatments

\begin{tabular}{ccccccc}
\hline Treatment & $\begin{array}{c}\text { Cell density at } \\
\text { beginning } \\
\left(\text { cells L }{ }^{-1}\right)\end{array}$ & $\begin{array}{c}\text { Cell density } \\
\text { in the end } \\
\left.(\text { cells L })^{-1}\right)\end{array}$ & $\begin{array}{c}\text { Copepod } \\
\text { individuals }\end{array}$ & $\begin{array}{c}\text { Incubation } \\
\text { time }\end{array}$ & $\begin{array}{c}\text { Filter Rate } \\
\left(\mathrm{mL} \mathrm{ind}^{-1} \mathrm{~h}^{-1}\right)\end{array}$ & $\begin{array}{c}\text { Grazing Rate } \\
\left(\mathrm{cells} \mathrm{ind}^{-1} \mathrm{~h}^{-1}\right)\end{array}$ \\
\hline $29^{\circ} \mathrm{C}$ & $4.16 \times 10^{4}$ & $(1.56 \pm 0.07) \times 10^{3}$ & 50 & $4 \mathrm{~h}$ & $2.59 \pm 0.04$ & $40.04 \pm 0.07$ \\
$33^{\circ} \mathrm{C}$ & $4.16 \times 10^{4}$ & $(2.46 \pm 0.11) \times 10^{3}$ & 50 & $4 \mathrm{~h}$ & $3.34 \pm 0.11$ & $40.14 \pm 0.11$ \\
$35^{\circ} \mathrm{C}$ & $4.16 \times 10^{4}$ & $(1.34 \pm 0.14) \times 10^{4}$ & 50 & $4 \mathrm{~h}$ & $0.44 \pm 0.11$ & $28.20 \pm 0.14$ \\
\hline
\end{tabular}


Table 2 (on next page)

Diversity indices of prey organisms in different Acartia erythraea samples 
1 Table 2 Diversity indices of prey organisms in different Acartia erythraea samples.

\begin{tabular}{llll}
\hline & $29{ }^{\circ} \mathrm{C}$ & $33^{\circ} \mathrm{C}$ & $35^{\circ} \mathrm{C}$ \\
\hline Taxa & 12 & 10 & 10 \\
Individuals/clones & 50 & 50 & 50 \\
Simpson_1-D & 0.752 & 0.64 & 0.7832 \\
Shannon_H & 1.768 & 1.566 & 1.819 \\
Chao-1 & 19 & 10 & 11 \\
\hline
\end{tabular}

2 


\section{Figure 1}

Phylogenetic affiliations and taxonomic distribution of the prey organisms in the copepod $A$. erythraea in different temperature treatments.

The phylogenetic tree was established for prey taxa with the ML method and 1000 bootstrap replicates, which was presented in the left part. The diet composition of $A$. erythraea from different temperatures was shown in the right part, and different colors represent the relative percentage of each prey group.

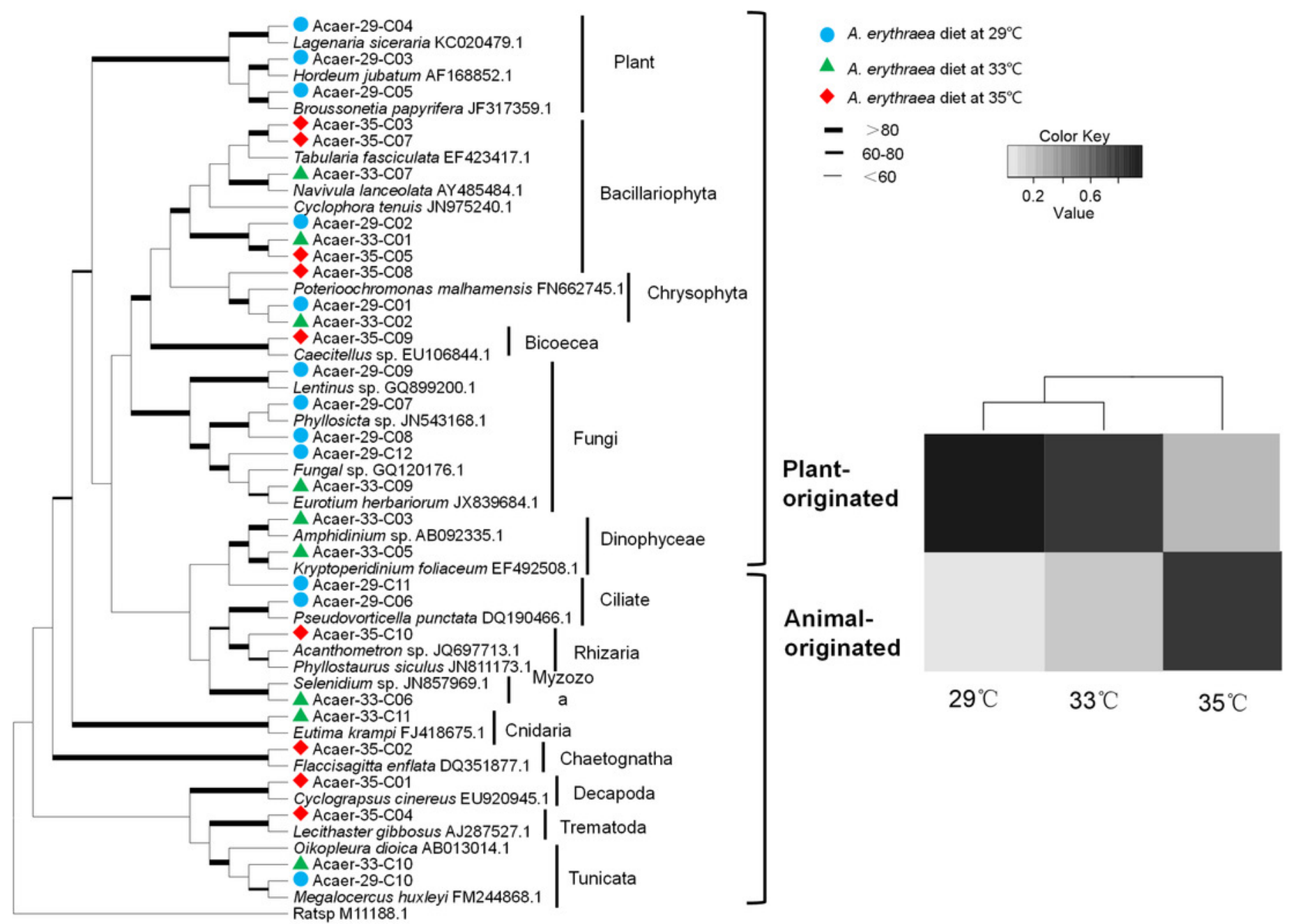


Figure 2

Ivlev Index of $A$. erythraea in different temperature treatments

Vege-prey represents dietary organisms from phytoplankton and land plants. 


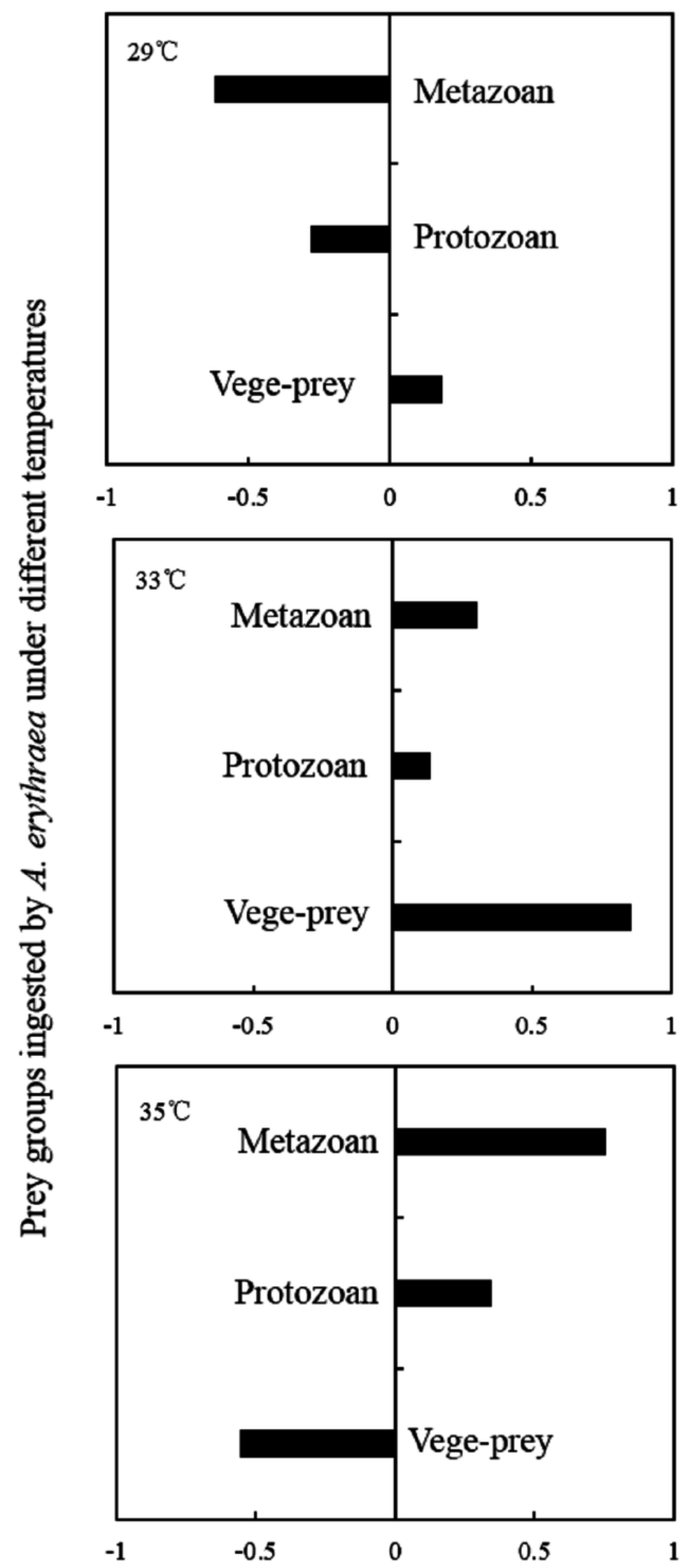

Peer) reviewing PDF | (201\$role97\$praleNEW 8 Nov 2018) 